Revista de Estudios Histórico-Jurídicos

[Sección derecho romano]

XXXIX (Valparaíso, Chile, 2017)

[pp. 85 - 110]

\title{
EN TORNO AL CARÁCTER (CUASI)CONTRACTUAL DE LA SOLUTIO INDEBITI EN LAS INSTITUCIONES DE GAYO
}

[On the (quasi) contractual nature of the solutio indebiti in the Institutes of Gaius]

\author{
Adolfo Wegmann Stockebrand* \\ Pontificia Universidad Católica de Chile
}

\begin{abstract}
RESUMEN
En sus Instituciones, Gayo presenta una summa divisio obligationum, según la cual toda obligación nace de un contrato o de un delito (Gai. 3,88). De acuerdo a este esquema, todo hecho lícito que genere obligaciones consiste en un contractus. Así es, en principio, tratándose del pago de lo no debido (solutio indebiti). Sin embargo, Gayo, luego de señalar que el adquirente de un pago indebido se obliga por la cosa del mismo modo que el mutuario (re obligatur), en circunstancia que el mutuo es para él un contrato (Gai. 3,90), manifiesta sus dudas respecto de la solutio indebiti, al señalar que quien paga por error lo que no debe, más quiere disolver una relación obligatoria (distrahere) que contraerla (contrahere), de modo que no pareciera que en la especie
\end{abstract}

\begin{abstract}
In his Institutes, Gaius presents a summa divisio obligationum, which states that every obligation either arises from a contract or from an offence (Gai. 3,88). Hence, any lawful event giving rise to obligations is a contractus. This is so, in principle, regarding the payment of what is not due (solutio indebiti). However, after Gaius indicates that the receiver of what was not owed from a person who pays in error is obligued as the borrower (re obligatur), because for him the simple loan is considered a contract (Gai. 3,90), he cast doubts on the solutio indebiti, by pointing out that he who pays in error what was not owed, rather wishes to extinguish an obligation (distrahere) than to establish one (contrahere), so that in this particular case
\end{abstract}

ReCiBIDO el 21 de diciembre de 2016 y ACEPTADO el 14 de junio de 2017

* Doctor en Derecho, Universidad de Heidelberg, Alemania. Profesor de derecho privado (derecho romano y derecho civil) en la Facultad de Derecho de la Pontificia Universidad Católica de Chile. Dirección postal: Avenida Libertador Bernardo OHiggins 340, Santiago, Chile. Correo electrónico: aawegman@uc.cl. Este artículo forma parte del proyecto Fondecyt Regular $N^{\circ} 1170316$, The Systematisation of Roman Law, del cual el autor es coinvestigador. 
se configure un contrato (Gai. 3,91). La atención de Gayo está puesta en todo caso no en la ausencia de conventio entre las partes, sino en la falta de intención de constituir una relación obligatoria, que no es lo mismo. Aquí se encuentra el germen de la futura categoría de los cuasicontratos en la tradición romanística.

\section{Palabras Clave}

Solutio indebiti-Contractus-Obligatio ex contractu - Quasi ex contractu - Re obligari-Instituciones de Gayo. it seems to be of a kind not arising from a contract (Gai. 3,91). Gaius does not focus on the absence of conventio between the parties, but on the lack of intent to establish an obligation, which is not the same. Here lies the origin of a future category of quasicontracts in civil law tradition.

KEYWORDS
Solutio indebiti-Contractus - Obligatio
ex contractu - Quasi ex contractu - Re
obligari-The Institutes of Gaius.

\section{INTRODUCCIÓN}

Si bien los sustantivos cuasicontrato y cuasidelito propiamente tales aparecen por primera vez en la Paráfrasis de Teófilo ${ }^{1}$, lo cierto es que la cuadripartición de las fuentes de las obligaciones en contrato, cuasicontrato, delito y cuasidelito ya se aprecia en la sistemática de las Instituciones de Justiniano, obra que precisamente era objeto de comentario por parte del maestro bizantino ${ }^{2}$. En efecto, el manual justinianeo nos enseña que las obligaciones nacen de un contrato, como de un contrato, de un delito o como de un delito: I. 3,13,2: "Sequens divisio in quattuor species deducitur: aut enim ex contractu sunt aut quasi ex contractu aut ex maleficio aut quasi ex maleficio".

El germen de las categorías del cuasicontrato y el cuasidelito ya se encuentra, por tanto, en el fragmento transcrito, como causas de obligación que podríamos calificar de análogas al contrato y al delito, en cuanto acto lícito no convencional que genera obligaciones el primero, y acto ilícito cometido sin intención de dañar el segundo. Una tradición clasificatoria distinta, de la que da cuenta Modestino, agrega como fuente de obligaciones la ley ${ }^{3}$. Estos textos constituyen el origen remoto-mediado, por cierto, por una tradición jurídica de ocho siglos, cuyo desarrollo no es objeto del presente estudio- de las cinco fuentes de las obligaciones mencionadas en el artículo 1437 del Código Civil chileno ${ }^{4}$. Entre las causas de obligación quasi ex contractu, las Instituciones de Justiniano mencionan el pago de lo no debido (solutio indebiti), no como figura desde un punto de vista que hoy

${ }^{1}$ PT. 3,27,3; 4,5pr.; 4,5,3.

2 Sobre las categorías de cuasicontrato y cuasidelito vid. por todos CannATA, Carlo Augusto, Quasi-contratti e quasi-delitti (storia), en ED., 38 (Milano, 1987), pp. 25 ss.

${ }_{3}$ D. 44,7,52,5 (Mod. 2 reg.): "Lege obligamur, cum obtemperantes legibus aliquid secundum praeceptum legis aut contra facimus".

${ }^{4}$ Art. 1437 CC: "Las obligaciones nacen, ya del concurso real de las voluntades de dos o más personas, como los contratos o convenciones; ya de un hecho voluntario de la persona que se obliga, como en la aceptación de una herencia o legado y en todos los cuasicontratos; ya a consecuencia de un hecho que ha inferido injuria o daño a otra persona, como en los delitos y cuasidelitos; ya por disposición de la ley, como entre los padres y los hijos sujetos a patria potestad'. 
llamaríamos material, sino que desde la perspectiva concreta de quien ha recibido una prestación indebida, contra el cual se puede ejercer una acción estrictamente restitutoria (la condictio) como si debiera en virtud de un contrato: "Item is cui quis per errorem non debitum solvit quasi ex contractu debere videtur" (I. 3,27,6).Lo anterior corresponde en lo esencial al encuadre sistemático del pago de lo no debido en nuestro Código Civil, donde se le califica expresamente como cuasicontrato5 ${ }^{5}$.

En el presente trabajo nos proponemos estudiar la posición sistemática de la solutio indebiti en las Instituciones de Gayo, en cuanto esta obra constituye, como es sabido, el principal modelo seguido en la elaboración del manual bizantino en general y de la así llamada tradición gayano-justinianea de clasificación de las fuentes de las obligaciones en particular. Nuestro interés por el texto gayano obedece a que en éste solo se reconocen como causas de obligación el contrato y el delito (Gai. 3,88: “omnis enim obligatio uel ex contractu nascitur uel ex delicto"), de modo tal que todo hecho lícito generador de obligaciones, como es el caso del pago de lo no debido, debería ser calificado como contractus, situación que ciertamente no se condice con la sistemática justinianea.

\section{ESTRUCTURA Y PROTECCIÓN PROCESAL DE LA SOLUTIO} INDEBITI

\section{Estructura}

En el orden sistemático de las Instituciones de Gayo, la solutio indebiti sigue a la exposición general de los elementos constitutivos de la mutui datio en cuanto (única) causa de obligatio re contracta, esto es, como supuesto de re contrahere, en Gai. 3,906. Nuestra fuente principal es, por tanto, Gai. 3,91, cuyo texto

5 Art. 2295 ss. CC. El art. 2285, segundo precepto del Título XXXIV "De los cuasicontratos", del Libro IV del Código Civil, dispone que "hay tres principales cuasicontratos: la agencia oficiosa, el pago de lo no debido y la comunidad". Al respecto vid. por todos BarRIENTOS GRANDON, Javier, El pago de lo no debido en el derecho chileno (Santiago, 2003).

6 "Re contrahitur obligatio uelut mutui datione; mutui autem datio proprie in his fere rebus contingit, quae res pondere, numero, mensura constant, qualis est pecunia numerata, uinum, oleum, frumentum, aes, argentum, aurum; quas res aut numerando aut metiendo aut pendendo in hoc damus, ut accipientium fiant et quandoque nobis non eaedem, sed aliae eiusdem naturae reddantur. unde etiam mutuum appellatum est, quia quod ita tibi a me datum est, ex meo tuum fit". Dan cuenta de la reducción del re contrahere al mutuo, además de Gayo en Gai. 3,90, Paulo en D. 2,14,17pr. (Paul. 3 ad ed.); nuevamente Gayo en D. 44,7,1,2 (Gai. 2 res cott.); Modestino en D. 44,7,52,1 y 3 (Mod. 2 reg.); Quinto Mucio Escévola (a través de Pomponio) en D. 46,3,80 (Pomp. 4 ad Q. Muc.); Labeón (por medio de Ulpiano) en D. 50,16,19 (Ulp. 11 ad ed.), en este último caso, sin embargo, hablando de re agere en vez de contrahere, por reducir Labeón la noción de contractus al ultro citroque obligatio, lo que excluye al mutuo, esencialmente unilateral; y el mismo Justiniano (al menos según el tenor literal del texto) en I. 3,14 pr. Una referencia indirecta a la mutui datio como causa de obligatio re contracta se encuentra, además, en Gai. 3,131, a propósito del nomen arcarium que, a diferencia del nomen transscripticium (mutuo ficticio), supone una efectiva numeratio pecuniae, de modo que la obligación no nace litteris, sino "re: Alia causa est eorum nominum, quae arcaria uocantur. in his enim rei, non litterarum obligatio consistit, quippe non aliter ualent, quam si numerata sit pecunia; numeratio autem pecuniae rei facit obligationem. qua de causa recte dicemus arcaria nomina nullam facere obligationem, sed obligationis factae testimonium praebere". La anotación del traspaso de dinero en el codex accepti 
completo transcribimos: Gai. 3,91: "Is quoque, qui non debitum accepit ab eo, qui per errorem solvit, re obligatur; nam proinde ei condici potest SI PARET EVM DARE OPORTERE, ac si mutuum accepisset. Unde quidam putant pupillum aut mulierem, cui sine tutoris auctoritate non debitum per errorem datum est, non teneri condictione, non magis quam mutui datione. Sed haec species obligationis non videtur ex contractu consistere, quia is, qui solvendi animo dat, magis distrahere vult negotium quam contrahere"7.

La solutio indebiti constituye, como su nombre lo indica, un supuesto de pago (solutio), esto es, la prestación de lo debido, la satisfacción de una acreencia. En el lenguaje de los clásicos, solvere y solutio significan, respectivamente, cumplir y cumplimiento ${ }^{8}$. En palabras de KASER, se trata del fin natural de una obligación a través de la ejecución de la prestación debida, la "realización de su finalidad existencial" (Verwirklichung ibres Daseinszwecks) ${ }^{9}$. En este orden de cosas, se aprecia una distinción entre la solutio, por una parte, y los demás modos de extinguir las obligaciones, que no necesariamente conllevan la satisfacción del interés del acreedor, por la otra ${ }^{10}$, si bien hay fuentes que dan cuenta de un uso del verbo solvere en sentido amplio, como disolución de una relación obligatoria en general y no como pago en especial ${ }^{11}$.

El extremadamente formalista derecho romano arcaico reconocía como

et expensi del acreedor no hace nacer la obligación, sino que solamente sirve como medio de prueba de la datio. En detalle sobre la noción romana clásica de obligatio re contracta, limitada al mutuo, y la consiguiente no clasicidad de la moderna noción de contrato real, que además del mutuo, comprende el comodato, el depósito y la prenda, WEGMANN STOCKEBRAND, Adolfo, Obligatio re contracta. Ein Beitrag zur sogenannten Kategorie der Realverträge im römischen Recht (Tübingen, 2017), esp. pp. 115 ss.

7 Para los rasgos esenciales de la solutio indebiti, descritos en la fuente citada, véase también D. 12,6,1,1 (Ulp. 26 ad ed.); D. 12,6,26,3 (Ulp. 26 ad ed.)(=FV. 266); D. 12,6,65,9 (Paul. 17 ad Plaut.).

${ }^{8}$ VIR. V, pp. 612 ss.; D. 50,16,176 (Ulp. $45 \mathrm{ad} \mathrm{Sab):} \mathrm{"S} \mathrm{o} \mathrm{l} \mathrm{u} \mathrm{t} i$ o $n$ is verbo satisfactionem quoque omnem accipiendam placet. S o l v e r e dicimus eum, qui fecit quod facere promisit". Cfr. también D. 46,3,54 (Paul. 56 ad ed.); D. 46,3,98,6 (Paul. 15 quaest.); D. 50,16,47 (Paul. 56 ad ed.). Sobre el significado de solvere-solutio en el derecho romano véase SARGENTI, Manlio, Pagamento (diritto romano), en ED., 31 (Milano, 1981), pp. 532 ss.; Longo, Giovanni Elio, Pagamento (diritto romano), en NNDI., 12 (Torino, 1965), pp. 316 ss.; CruZ, Sebastião, Da 'solutio'. Terminologia, conceito e características, e análise de vários institutos afins, I: Épocas arcaica e clássica (Coimbra, 1962), esp. pp. 57 ss.; SolazzI, Siro, L'estinzione dell'obbligazione nel diritto romano (2a edición, Napoli, 1935), I, pp. 9 ss.; Kretschmar, Paul, Die Erfüllung. Erster Teil. Historische und dogmatische Grundlagen (Leipzig, 1906), pp. 1 ss.

${ }^{9}$ KASER, Max, Das Römische Privatrecht (2a edición, München, 1971), I, p. 635; en términos similares Cruz, Sebastião, Da 'solutio', cit. (n. 8), pp. 60 ss., 355 ss.

${ }^{10}$ Cfr. Arangio-Ruiz, Vincenzo, Istituzioni di diritto romano (14a edición, Napoli, 1960), p. 392.

${ }^{11}$ Así se aprecia, por ejemplo, en D. 46,3,80 (Pomp. 4 ad Q. Muc.): "Prout quidque contractum est, ita et solvi debet III [...]". Sobre la fuente vid. por ejemplo FIORI, Roberto, Contrahere e solvere obligationem in Q. Mucio Scevola, en Cascione/MasI DORIA (eds.), Fides humanitas ius. Studii in onore di Luigi Labruna (Napoli, 2007), III, pp. 1955 ss.; SANTORO, Raimondo, Su D. 46.3.80 (Pomp. 4 ad Quintum Mucium), en AUPA., 55 (2012), pp. 553 ss.; en ambos casos, con un detallado análisis crítico de la literatura más antigua. 
modo de pago solamente la nexi liberatio o solutio per aes et libram ${ }^{12}$. La posterior evolución del ius civile trajo consigo la paulatina superación de este estado de cosas en favor de la posibilidad de cumplir las obligaciones por medio de un pago exento de formalidades, en la medida que éstas no fueran exigidas por la estructura misma de la relación obligatoria que se quería extinguir. De esta manerala solutio, en el marco de un contrato de mutuo informal, esto es, presumiblemente a partir de la introducción del agere per condictionem por medio de las leyes Silia y Calpurnia ${ }^{13}$, con lo cual la protección procesal de la mutui datio ya no dependía de su revestimiento bajo la forma de una stipulatio, consistía en la entrega informal translaticia de dominio (datio rei) por parte del mutuario de la misma cantidad -de dinero (certa pecunia) u otros bienes fungibles (res, quae pondero numero mensura constant) según el caso- que había sido dada en crédito por el mutuante (tantundem eiusdem generis), de acuerdo al así llamado principio de simetría ${ }^{14}$ : retro pecuniae tantundem solvere ${ }^{15}$.

Sin embargo, puede ocurrir que la obligación que se pretende cumplir no exista en absoluto, o bien, que existiendo, quien paga (solvens) no sea realmente deudor de la persona que recibe el pago (accipiens) ${ }^{16}$. Se trata, por consiguiente, de una inexistencia objetiva o subjetiva de la obligatio que se busca extinguir. Si el referido pago ha tenido lugar en virtud de un error del solvens, estamos en presencia de una solutio indebiti, un pago de lo no debido. En consecuencia, habrá pago de lo no debido cada vez que una persona cumpla por error ("[...] qui per errorem solvit)" algo indebido (indebitum), ya sea porque la obligación no llegó a nacer en absoluto, o porque habiendo existido se ha extinguido, o porque no

${ }^{12}$ XII Tab. 1,6; 8,2; Gai. 3,173 ss.; Cic., De leg. 2,20,51; 2,21,53. Vid. por ejemplo AlBANESE, Bernardo, Gli atti negoziali nel diritto privato romano (Palermo, 1982), pp. 66 s.; SARGENTI, Manlio, Pagamento, cit. (n. 9), pp. 532 ss. Una breve exposición de conjunto en KaSER, Max, Das Römische Privatrecht, cit. (n. 9), pp. 171 ss.

13 Gai. 4,19:"Haec autem legis actio constituta est per legem Siliam et Calpurniam, lege quidem Silia certae pecuniae, lege vero Calpurnia de omni certa re”. Vid. por ejemplo FrEZZA, Paolo, Storia del processo civile in Roma fino alla età di Augusto, en ANRW., I/2 (Berlin/New York, 1972), pp. 172 ss.; BeHrends, Okko, Der Zwölftafelprozess (Göttingen, 1974), pp. 97 ss.; AlbANEse, Bernardo, Il processo privato romano delle legis actiones (Palermo, 1987), pp. 110 ss.; KASER, Max/HackL, Karl, Das Römische Zivilprozessrecht (2a edición, München, 1996), pp. 111 ss.

${ }^{14}$ Sobre este principio vid. especialmente ScHMidun, Bruno, Die römischen Rechtsregeln. Versuch einer Typologie (Köln/Wien, 1970), pp. 74 ss.; KNÜTEL, Rolf, Zum Prinzip der formalen Korrespondenz im römischen Recht, en ZSS., 88 (1971), pp. 98 ss.; NöRR, Dieter, Spruchregel und Generalisierung, en ZSS., 89 (1972), p. 60. Cfr. también, para la literatura más reciente, SANTORo, Raimondo, Su D. 46.3.80, cit. (n. 11), pp. 555 ss.; CORTESE, Barbara, Indebiti solutio ed arricchimento ingiustificato. Modelli storici, tradizione romanistica e problemi attuali (2a edición, Napoli, 2013), p. 98.

15 D. 46,3,80 (Pomp. 4 ad Q. Muc.): "Prout quidque contractum est, ita et solvi debet: ut, cum re contraxerimus, re solvi debet: veluti cum mutuum dedimus, ut retro pecuniae tantundem solvi debeat $[\ldots] ”$.

${ }^{16}$ Así lo expresa claramente Paulo en D. 12,6,65,9 (Paul. 17 ad Plaut.): “Indebitum est non tantum, quod omnino non debetur, sed et quod alii debetur, si alii solvatur, aut si id quod alius debebat alius quasi ipse debeat solvat". Una exégesis detallada de la fuente en PELLECCHI, Luigi, L'azione di ripetizione e le qualificazioni del dare in Paul. 17 ad Plaut. D. 12.6.65. Contributo allo studio della condictio, en SDHI., 64 (1998), pp. 69 ss. 
puede exigirse su cumplimiento en virtud de una exceptio perpetua (así llamado indebitum pretorio) ${ }^{17}$. Dicho en otros términos: en la solutio indebiti la obligación no existe objetivamente, o bien quien paga no es el verdadero deudor, o siéndolo, no puede ser constreñido a dicho pago en virtud de la oponibilidad de una excepción perpetua. De esta guisa, son elementos de la solutio indebiti el acto de pagar (solvere en sentido estricto) un indebitum (objetivo o subjetivo), por una parte, y una falsa representación de la realidad (error) que induce al solvens a efectuar la prestación, por la otra ${ }^{18}$. El error supone que el pago se realizó sin tener perfecto conocimiento de lo que se hacía; de lo contrario, se excluye la posibilidad de repetir: "[...] sed si sciens se non debere solvit, cessat repetitio" ${ }^{19}$. Con todo, el pago de lo no debido que no se encuentra motivado por un error no es constitutivo de donación, aunque ciertamente se trate de situaciones muy cercanas ${ }^{20}$. El error del accipiens, si bien no se exige estructuralmente para que el pago sea calificado de indebido, debe concurrir igualmente, puesto que de lo contrario, al recibir el falso acreedor a sabiendas lo que no se le debe, comete hurto (furtum). Se trata, pues, de una hipótesis de hurto que no se basa en la sustracción de bienes muebles ajenos (amotio, supuesto normal de furtum), sino en la mera contrectatio. ${ }^{21}$

El análisis de las fuentes jurídicas romanas relativas al pago de lo no debido

${ }^{17}$ Lo sabemos gracias a un fragmento con doble tradición textual. FV. 266: "Indebitum solutum accipimus non solum si omnino non debebatur, sed et si per aliquam exceptionem peti non poterat, id est perpetuam exceptionem. Quare hoc quoque repeti poterit, si quis perpetua exceptione totus solverit [...]”. En la compilación justinianea, el texto corresponde a D. 12,6,26,3 (Ulp. 26 ad ed.).

${ }^{18}$ Cfr. Schwarz, Fritz, Die Grundlage der Condictio im klassischen römischen Recht (Münster/ Köln, 1952), pp. 7 ss.; ARCHI, Gian Gualberto, Variazioni in tema di indebiti solutio, en Studi in onore di Vincenzo Arangio Ruiz (Napoli, 1953), III, pp. 335 ss.; recientemente CORTESE, Barbara, Indebiti solutio ed arricchimento ingiustificato, cit. (n. 14), pp. 97 ss.

${ }_{19}$ D. 12,6,1,1 (Ulp. 26 ad ed.): "Et quidem si quis indebitum ignorans solvit, per hanc actionem condicere potest: sed si sciens se non debere solvit, cessat repetition". En el mismo sentido D. 12,6,50 (Pomp. 5 ad Q. Muc.): "Quod quis sciens indebitum dedit hac mente, ut postea repeteret, repetere non potest".

${ }^{20}$ Cfr. D. 46,2,12 (Paul. 31 ad ed.). Vid. Schwarz, Fritz, Die Grundlage der Condictio, cit. (n. 18), pp. 111 ss.; ArCHI, Gian Gualberto, La donazione. Corso di diritto romano (Milano, 1960), pp. 121 ss.; KASER, Max, Das Römische Privatrecht, cit. (n. 9), p. 596, n. 36; CANNATA, Carlo Augusto, Cum alterius detrimento et iniuria fieri locupletiorem. L'arricchimento ingiustificato nel diritto romano, en VACCA (ed.), Arricchimento ingiustificato e ripetizione dell'indebito. VI Convegno Internazionale ARISTEC. Padova-Verona-Padova, 25-26-27 settembre 2003 (Torino, 2005), p. 18. Nuestro Código Civil se refiere expresamente a esta situación, exigiendo el pleno conocimiento por parte del solvens de que da lo que no debe para que pueda presumirse que en la especie se configura una donación. Art. 2299 CC.: "Del que da lo que no debe, no se presume que lo dona, a menos de probarse que tuvo perfecto conocimiento de lo que hacía, tanto en el hecho como en el derecho". Cfr. art. 1397 CC.i.f.: "[...] hace donación el que remite una deuda, o el que paga a sabiendas lo que en realidad no debe".

${ }^{21}$ D. 13,1,18 (Scaev. 4 quaest.): "Quoniam furtum fit, cum quis indebitos nummos sciens acceperit, videndum, si procurator suos nummos solvat, an ipsi furtum fiat. Et Pomponius epistularum libro octavo ipsum condicere ait ex causa furtiva: sed et me condicere, si ratum habeam quod indebitum datum sit. sed altera condictione altera tollitur". Véase también D. 47,2,43pr. (Ulp. 41 ad Sab.) y D. 47,2,44pr. (Pomp. 11 ad Sab.). En detalle sobre esta situación Fargnoli, Iole, Ricerche in tema di furtum. Qui sciens indebitum accipit (Milano, 2006). Cfr. también KASER, 
muestra con meridiana claridad que la jurisprudencia clásica vio en la solutio indebiti específicamente el pago erróneo de obligaciones inexistentes -objetiva o subjetivamente- de darerem, esto es, aquellas que consisten en la transferencia del dominio civil sobre una cosa (dare oportere) ${ }^{22}$. Lo dicho se desprende inequívocamente de Gai. 3,91, donde el maestro antoniniano se refiere explícitamente a esta clase de obligaciones: "[...] si paret eum dare oportere". Lo mismo puede decirse de los fragmentos jurisprudenciales incorporados por los compiladores al título sexto del décimo segundo libro del Digesto, que lleva el justinianeo nombre de condictione indebiti, todos los cuales discurren sobre la base de que la obligación que se creía cumplir consistía en un dare oportere. Como es sabido, la condictio clásica era una acción única, cuya abstracción formularia la hacía susceptible de ser empleada para fines estrictamente restitutorios (quanti ea res est) a partir de causae muy disímiles ${ }^{23}$. Procedía en casos que tenían como rasgo común la retención injusta de una cosa, que obligaba a restituirla, ya fuera porque la causa retinendi nunca existió (sine causa), porque existiendo, era ilícita (ex iniusta causa), porque existió y luego desapareció (llegada del plazo para restituir las cosas recibidas en mutuo, supuestos de causa data causa non secuta), etc. Ahora bien, estos casos de detentación injusta debían fundarse en un previo acto de transferencia patrimonial, esto es, en un acto del dans, no habiendo causa retinendi-inicial o sobreviniente- del accipiens. En el derecho justinianeo, sin embargo, la condictio clásica aparece desmembrada en distintas acciones con nombre propio, cada cual según el motivo que daba lugar a la obligación de restituir ${ }^{24}$, y así se denominó condictio indebiti la acción con la cual se exigía la restitución de la cantidad de dinero o el simple valor de las cosas transferidas indebidamente en cumplimiento de una obligación inexistente, y de condictione indebiti al título del Digesto que trataba esta materia más o menos sistemáticamente. Pues bien, el hecho es que en

Max, Zur 'iusta causa traditionis', en BIDR., 64 (1961), p. 76; Cannata, Carlo Augusto, Cum alterius detrimento et iniuria fieri locupletiorem, cit. (n. 20), p. 19.

${ }^{22}$ Que el sentido técnico-jurídico de dare rem (dare oportere) consiste en transferir el dominio quiritario de una cosa y no en su mera entrega, se desprende inequívocamente de, por ejemplo, Gai. 2,204; 4,4; D. 17,1,47,1 (Pomp. 3 ex Plaut.); D. 22,1,4pr. (Pap. 27 quaest.); D. 32,29,3 (Lab. 2 post. a Iav. epit.); D. 45,1,75,10 (Ulp. 22 ad ed.); D. 50,17,167pr. (Paul. 49 ad ed.). Se trata de fuentes que dan cuenta de las distintas etapas y orientaciones de la jurisprudencia clásica, las que se mantienen, sin embargo, contestes en este punto. Cfr. Grosso, Giuseppe, Obbligazioni. Contenuto e requisiti della prestazione, obbligazioni alternative e generiche ( $2^{\mathrm{a}}$ edición, Torino, 1955), pp. 19 ss.; PASTORI, Franco, Concetto e struttura della obbligazione nel diritto romano (Milano, 1985), pp. 131 ss.

${ }^{23} \mathrm{La}$ abstracción de la fórmula se aprecia especialmente en Gai. 4,17b: "Per condictionem ita agebatur: AIO TE MIHI SESTERTIORVM X MILIA DARE OPORTERE [...]”; y Gai. 4,41: "Intentio est ea pars formulae, qua actor desiderium suum concludit, uelut haec pars formulae: SI PARET NVMERIVM NEGIDIVM AVLO AGERIO SESTERTIVM X MILIA DARE OPORTERE [...]”. Para la reconstrucción de la fórmula vid. por todos LENEL, Otto, Das Edictum Perpetuum. Ein Versuch zu seiner Wiederherstellung (3a edición, Leipzig, 1927), pp. 232 ss; cfr. también Mantovani, Dario, Le formule del processo privato romano. Per la didattica delle Istituzioni di diritto romano (2a edición, Padova, 1999), pp. $48 \mathrm{~s}$.

${ }^{24}$ En detalle sobre esta evolución SACCOCCIO, Antonio, Si certum petetur. Dalla condictio dei veteres alle condictiones giustinianee (Milano, 2002), pp. 549 ss. 
los textos que forman parte de D. 12,6 se habla exclusivamente de obligaciones de dare en sentido técnico-jurídico de transferencia de dominio, la mayoría de las veces con respecto a una cantidad cierta de dinero (certa pecunia $)^{25}$.

De la circunstancia que a la base de la solutio indebiti no hay una obligación válidamente contraída o, al menos, exigible, en una primera aproximación podría creerse que esta figura no implica la efectiva transferencia del dominio sobre las cosas dadas en pago al accipiens; lo anterior, porque la traditio supone para operar como modo de adquirir el dominio y no como mera forma de adquirir la posesión, una causa conforme a derecho (iusta causa traditionis) ${ }^{26}$. Ahora bien, lo cierto es que las fuentes son claras al afirmar precisamente lo contrario: las cosas entregadas en cumplimiento de una obligación de dar son transferidas, aun cuando el vínculo jurídico que se busca extinguir no haya existido en absoluto. Esta solución obedece al hecho que en los supuestos de pago de lo no debido los juristas romanos vieron la iusta causa traditionis no en la obligación que erróneamente se creía cumplir, sino que en el pago mismo ${ }^{27}$. Dicho en otros términos, lo que se da, por ejemplo, en cumplimiento de una estipulación, no se transfiere ex causa stipulationis, sino ex causa solvendi $i^{28}$. De ahí que la solutio indebiti constituya una efectiva datio rei, y así es tratada consecuentemente en las fuentes ${ }^{29}$.

${ }^{25}$ Véase por ejemplo D. 12,6,15,1 (Paul. 10 ad Sab.); D. 12,6,19,2 y 4 (Pomp. 22 ad Sab.); D. 12,6,21 (Paul. 3 quaest.); D. 12,6,25 (Ulp. 47 ad Sab.); D. 12,6,26pr.-2 (Ulp. 26 ad ed.); D. 12,6,47 (Cels. 6 dig.); D. 12,6,57,1 (Pap. 3 resp.); D. 12,6,67pr. (Scaev. 5 dig.). Cfr. en otros títulos del Digesto, por ejemplo, D. 12,4,9,1 (Paul. 17 ad Plaut.); D. 12,4,14 (Paul. 3 ad Sab.); D. 13,1,18 (Scaev. 4 quaest.). A diferencia de la mutui datio, la solutio indebiti puede referirse a cosas no fungibles, de lo que resulta que la obligación de restitución del accipiens puede tener por objeto la res ipsa y no solo el tantundem eiusdem generis, como enseña Pomponio en D. 12,6,7 (Pomp. 9 ad Sab.): "Quod indebitum per errorem solvitur, aut ipsum aut tantundem repetitur". Cfr. D. 12,6,15pr.-1 (Paul. 10 ad Sab.).

${ }^{26}$ Sobre la necesidad de causa para la tradición en cuanto modo de adquirir el dominio, véase D. 41,1,31pr. (Paul. 31 ad ed.): "Numquam nuda traditio transfert dominium, sed ita, si venditio aut aliqua iusta causa praecesserit, propter quam traditio sequeretur". En términos semejantes se expresa Gayo, Gai. 2,20: "Itaque si tibi vestem vel aurum vel argentum tradidero sive ex venditionis causa sive ex donationis sive quavis alia ex causa, statim tua fit ea res, si modo ego eius dominus sim". Sobre la iusta causa traditionis y el problema de la solutio indebiti véase en detalle KASER, Max, Zur 'iusta causa traditionis', cit. (n. 21), pp. 61 ss.; JAHR, Günther, Zur iusta causa traditionis, en ZSS., 80 (1963), pp. 141 ss.; CANNATA, Carlo Augusto, Cum alterius detrimento et iniuria fieri locupletiorem, cit. (n. 20), pp. 18 ss.; VACCA, Letizia, Osservazioni in tema di 'condictio' e 'arricchimento senza causa' nel diritto romano classico, en D'IPPOLITO (ed.), Фi $\lambda i$ í. Scritti per Gennaro Franciosi (Napoli, 2007), IV, pp. 2714 ss.; CORTESE, Barbara, Indebiti solutio ed arricchimento ingiustificato, cit. (n. 14), pp. 100 ss.

${ }^{27}$ KASER, Max, Zur 'iusta causa traditionis', cit. (n. 21), pp. 69 ss. En este sentido, la opinión de SAnfilippo, Cesare, Condictio indebiti I. Il fondamento dell'obbligazione da indebito (Milano, 1943), pp. 76 ss., en cuanto a que el presupuesto para ejercer la así llamada condictio indebiti sería una datio sine causa, es terminológicamente imprecisa.

${ }^{28}$ Sobre la cuestión de la solutio como iusta causatraditionis véase recientemente LABORENZ, Martin, Solutio als causa. Die Frage des Abstraktionsprinzips im römischen Recht (Köln/Weimar/ Wien, 2014), pp. 90 ss.

${ }^{29}$ Cfr. KASER, Max, Zur 'iusta causa traditionis', cit. (n. 21), pp. 70 ss. Vid. también KuPISCH, Berthold, Ungerechtfertigte Bereicherung. Geschichtliche Entwicklungen (Heidelberg, 1987), pp. 16 ss.; Cannata, Carlo Augusto, Cum alterius detrimento et iniuria fieri locupletiorem, cit. (n. 


\section{Protección procesal}

Como se ha adelantado, en términos generales se puede ejercer la condictio toda vez que concurre una datiorei y el accipiens carece de fundamento jurídico suficiente para la retención de la cosa por él adquirida (causa retinendi) ${ }^{30}$. Con todo, los juristas romanos reconocieron la procedencia de la condictio también en ciertos casos en los cuales no había tenido lugar una datio, esto es, supuestos de la así llamada condictio sine datione $e^{31}$, solución quese remontaría a la doctrina de los veteres, según el testimonio de Ulpiano ${ }^{32}$. En materia de solutio indebiti, indudablemente se trata de una datio rei; en efecto, Gayo se refiere en términos explícitos a una prestación de dar: "[...] nam proinde ei condici potest si paret eum dare oportere". Consecuencialmente, el pago de lo no debido trae consigo la transferencia de dominio quiritario sobre la cosa dada en cumplimiento de la (supuesta) obligación; este es el motivo por el cual el solvens puede ejercer la acción de restitución en contra del accipiens. De ahí que consideremos equivocada la opinión de LABORENZ, en el sentido que Gai. 3,91 se referiría únicamente a la función de la solutio indebiti en cuanto desencadenante del ejercicio de la condictio y no de un negocio que implica la transferencia de propiedad, como si se tratara de dos cosas completamente distintas y susceptibles de separación ${ }^{33}$. Gayo, en cambio, se refiere a la solutio indebiti expresamente como el cumplimiento erróneo de una obligación de dar (dare oportere) inexistente, esto es, como un acto de transferencia del dominio, ya que de las fuentes clásicas -entre ellas, algunas del propio

20), pp. 18 ss. Equívoco Voci, Pasquale, La dottrina romana del contratto (Milano, 1946), p. 117 , quien con respecto a la datio afirma que "[...] è chiaro che causa qui non esiste [...]" (p. 117), para algunas líneas más abajo sostener que "la causa petendi è nel fatto dell'arricchimento del convenuto: solo, ch'è stabilito il modo dell'arricchimento: deve avvenire mediante una datio" (p. 118).

${ }^{30}$ Para el caso de la solutio indebiti en particular véase en detalle FARGNOLI, Iole, 'Alius solvit, alius repetit'. Studi in materia di indebitum condicere (Milano, 2001); CORTESE, Barbara, 'Quod sine iusta causa apud aliquem est potest condici'(Napoli, 2013).

${ }^{31}$ Vid. por todos HeIne, Sonja, Condictio sine datione. Zur Haftung aus ungerechtfertigter Bereicherung im klassischen römischen Recht und zur Entstehung des Bereicherungsrechts im BGB (Berlin, 2006). Un claro ejemplo de condictio no precedida de una datio es la concesión a la víctima de un hurto de la condictio (ex causa furtiva), de que da cuenta Gai. 4,4: "[...] plane odio furum, quo magis pluribus actionibus teneantur, receptum est, ut extra poenam dupli aut quadrupli rei recipiendae nomine fures etiam hac actione teneantur [...]". En detalle sobre este supuesto PIKA, Wolfram, Ex causa furtiva condicere im klassischen römischen Recht (Berlin, 1988). Niega la existencia de la condictio sine datione en el derecho romano clásico D'ORs, Réplicas Panormitanas IV. Sobre la supuesta 'condictio' sin 'datio', en Iura, 25 (1974), pp. 1 ss., en cuya opinión se trataría más bien de dationes ex eventu u ob causam.

${ }^{32}$ D. 12,5,6 (Ulp. 18 ad Sab.): "Perpetuo Sabinus probavit veterum opinionem existimantium id, quod ex iniusta causa apud aliquem sit, posse condici: in qua sententia etiam Celsus est". Sobre la fuente véase por ejemplo HeINE, Sonja, Condictio sine datione, cit. (n. 31), pp. 111 ss.; SACCoccio, Antonio, Si certum petetur, cit. (n. 24), pp. 98 ss.; HäHnCHEN, Susanne, Sab.-Ulp. D. 12,5,6 und die condictio ex iniusta causa, en ZSS., 121 (2004), pp. 385 ss.; CORTESE, Barbara, 'Quod sine iusta causa, cit. (n. 30), pp. 41 ss.

33 Laborenz, Martin, Solutio als causa, cit. (n. 28), p. 236. 
Gayo- se desprende en términos inequívocos que el significado técnico-jurídico de dare consiste en entregar una cosa transfiriendo el dominio civil sobre ella ${ }^{34}$.

La transferencia de la propiedad de las cosas entregadas erróneamente por el solvens al falso acreedor es válida, pero injustificada; el accipiens carece de fundamento jurídico suficiente para conservar dichas cosas y contrae por consiguiente la obligación de restituir la misma cantidad de dinero o el simple valor de las cosas recibidas en pago $^{35}$, la que se hace valer por medio de la condictio $^{36}$. En esta específica situación radica la causa petendi del solvens. A lo dicho se puede agregar que la condictio encuentra su fundamento también en la regla según la cual nadie puede enriquecerse injustificadamente a partir del daño sufrido por otro $^{37}$. Es por esta razón que la condictio usualmente ha sido vista como la base del derecho contra el enriquecimiento injustificado (Bereicherungsrecht, en el mundo de lengua alemana $)^{38}$, sin duda una generalización excesiva cuando se analiza el problema con perspectiva histórica: los antiguos romanos nunca llegaron a desarrollar un modelo unificado de derecho del enriquecimiento injusto; la situación moderna de reglamentación sistemática del fenómeno, cuyo caso emblemático es Alemania $^{39}$, se basa en una evolución plurisecular a partir de soluciones concretas implementadas por la jurisprudencia romana (el paso del casus a la regula, típico

34 Vid. supra n. 22.

35 Cfr. Sanfilippo, Cesare, Condictio indebiti, cit. (n. 27), p. 52, 87 ss.; Schwarz, Fritz, Die Grundlage der Condictio, cit. (n. 18), pp. 191 ss.; KASER, Max, Zur 'iusta causa traditionis', cit. (n. 21), pp. 70 ss.; KUPISCH, Berthold, Ungerechtfertigte Bereicherung, cit. (n. 29), pp. 4 ss.

${ }^{36}$ Gai. 3,91. Cfr. D. 12,6,1,1 (Ulp. 26 ad ed.); D. 12,6,2pr. (Ulp. 16 ad Sab.); D. 12,6,6pr.3 (Paul. 3 ad Sab.); D. 12,6,16pr. (Pomp. 15 ad Sab.). Vid. por ejemplo Giuffrè, Vincenzo, Studi sul debito tra esperienza romana e ordinamenti moderni (2a edición, Napoli, 1999), p. 11; FARGNOLI, Iole, 'Alius solvit, alius repetit', cit. (n. 30), pp. 10 ss.; SaCCOCCIO, Antonio, Si certum petetur, cit. (n. 24), pp. 489 ss, 520 ss; HäHNCHEN, Susanne, Die causa condictionis. Ein Beitrag zum klassischen römischen Kondiktionenrecht (Berlin, 2003), pp. 73 ss.; VACCA, Letizia, Osservazioni in tema di 'condictio', cit. (n. 26), pp. 2714 ss.

37 D. 12,6,14 (Pomp. 21 ad Sab.): "Nam hoc natura aequum est neminem cum alterius detrimento fieri locupletiorem"; en términos casi idénticos D. 50,17,206 (Pomp. 9 ex var. lect.): "Iure naturae aequum est neminem cum alterius detrimento et iniuria fieri locupletiorem". Véase también D. 12,6,66 (Pap. 8 quaest.): "Haec condictio ex bono et aequo introducta, quod alterius apud alterum sine causa deprehenditur, revocare consuevit". Vid. VACCA, Letizia, Osservazioni in tema di 'condictio', cit. (n. 26), pp. 2709 ss.; HeIne, Sonja, Condictio sine datione, cit. (n. 31), pp. 111 ss.; Cannata, Carlo Augusto, Materiali per un corso di fondamenti del diritto europeo (Torino, 2005), I, pp. 90 ss.; ÉL MISMO, Cum alterius detrimento et iniuria fieri locupletiorem, cit. (n. 20), pp. 20 ss.; HäHnchen, Susanne, Sab.-Ulp. D. 12,5,6, cit. (n. 32), pp. 385 ss.; LA MISMA, Die causa condictionis, cit. (n. 36), pp. 58 ss.; HARKE, Jan Dirk, Das klassische römische Kondiktionensystem, en Iura 54 (2003), pp. 49 ss.; SANTORO, Raimondo, Studi sulla condictio, en AUPA., 32 (1971), pp. 190 ss. Schwarz, Fritz, Die Grundlage der Condictio, cit. (n. 18), pp. 302 ss. no considera clásica la referencia a la equidad como fundamento de la condictio. En el mismo sentido ya Pringsheim, Fritz, Bonum et aequum, en ZSS., 52 (1932), pp. 139 ss.

38 En este sentido vid. por ejemplo Von Koschembahr-Lyskowski, Ignacy, Die Condictio als Bereicherungsklage im klassischen römischen Recht (Weimar, 1903); KUPISCH, Berthold, Ungerechtfertigte Bereicherung, cit. (n. 29), pp. 15 ss.

39 Vid. $\$ \$ 812-822$ BGB. 
del ius commune), entre las cuales el ejercicio de la condictio indebiti ostenta un sitial de privilegio ${ }^{40}$. Nada menos, pero tampoco nada más.

\section{LA SOLUTIO INDEBITI EN EL ESQUEMA GAYANO DE LAS}

\section{CAUSAE OBLIGATIONUM Y EL RE OBLIGARI}

\section{Obligación real nacida de solutio indebiti? Velut}

Como hemos dicho más arriba, se contrae una obligación real a través de la dación en mutuo: "re contrahitur obligatio velut mutui datione" (Gai. 3,90). Gayo utiliza, empero, la partícula velut, cuyo significado dista de ser unívoco. Ésta puede ser interpretada de dos maneras, radicalmente distintas la una de la otra; de hecho, opuestas: en el sentido de a saber, en concreto, o bien, como por ejemplo. Según la primera hipótesis interpretativa, la frase "re contrahitur obligatio velut mutui datione" podría ser traducida en los siguientes términos: "se contrae una obligación real, a saber len concreto, por medio de la dación en mutuo”. En el segundo caso, en cambio, la misma frase significaría "se contrae una obligación real, por ejemplo, por medio de la dación en mutuo". Como puede apreciarse, en la primera propuesta de traducción el texto expresa que la dación en mutuo es la única forma de contraer una obligación real; la segunda, en cambio, hace alusión indirectamente a otros supuestos de obligatio re contracta, distintos de la nacida de mutuo, mencionándose este último solo a título de ejemplo.

En otro trabajo hemos intentado demostrar que la partícula velut contenida en Gai. 3,90, si se refiere específicamente al re contrahere en especial y no al re obligari en general, debe ser entendida en sentido restrictivo, es decir, como a saber o en concreto ${ }^{41}$. La absoluta inexistencia de fuentes jurídicas romanas, tanto dentro como fuera de la compilación justinianea, en las cuales se utilice el sintagma re contrahere en alguna de sus formas posibles para figuras distintas del mutuum, avala nuestra traducción de velut en Gai. 3,90: la mutui datio no es un simple ejemplo de causa de obligatio re contracta, sino la única. Así, al menos para el derecho romano clásico ${ }^{42}$. Sin embargo, Gayo nos hace saber que el mutuo no es el único fundamento de una obligación real en general, ya que acto seguido incluye en la misma categoría a la obligación de restitución del accipiens de un

${ }^{40}$ ZIMMERMANN, Reinhard, Ungerechtfertigte Bereicherung und das common law, en VACCA (ed.), Arricchimento ingiustificato e ripetizione dell indebito. VI Convegno Internazionale ARISTEC. Padova-Verona-Padova, 25-26-27 settembre 2003 (Torino, 2005), p. 255.

41 Wegmann Stockebrand, Adolfo, Obligatio re contracta, cit.(n. 6), pp. 131 ss. Cfr. también BETTI, Emilio, Sul significato di 'contrahere' in Gaio e sulla non-classicità della denominazione 'quasi ex contractu obligatio', en BIDR., 25 (1912), p. 66; FERrINI, Contardo, Storia e teoria del contratto di commodato nel diritto romano, citado de Opere (Milano, 1929), III, p. 81; VocI, Pasquale, La dottrina romana, cit. (n. 29), p. 121; Magdelain, André, Le consensualisme dans l'édit du préteur (Paris, 1958), p. 96 (n. 219); MAsCHI, Carlo Alberto, Tutela, fedecommessi, contratti reali (Omissioni nel manoscritto veronese delle Istituzioni di Gaio) en Studi in onore di Edoardo Volterra IV (Milano, 1971), p. 725; ÉL MISMO, La categoria dei contratti reali. Corso di diritto romano (Milano, 1973), p. 249.

${ }^{42}$ En detalle sobre esta cuestión, desde el punto de vista del autor, WEGMANN STOCKEBRAND, Adolfo, Obligatio re contracta, cit. (n. 6), pp. 115 ss. 
indebitum: "Is quoque, qui non debitum accepit ab eo, qui per errorem soluit, re obligatur". Con esto, seguramente Gayo quiso aludir al hecho que la mutui datio no es la única causa de obligación real en términos absolutos, pero sí su fuente prototípica, en cuanto único caso de obligación contraída re.

De Gai. 3,91 se desprende que la solutio indebiti se encuentra estrechamente unida en su estructura a la mutui datio; de ahí que pueda ser calificada propiamente como causa de una obligación real, por más que en el texto se recurra a una expresión indeterminada como re obligari, cuyo horizonte semántico ciertamente es más amplio que el de re contrahere, reservado este último al mutuo ${ }^{43}$. De hecho, Gayo no duda en hacer explícita esta vinculación entre ambas figuras, al señalar que se concede la condictio contra el accipiens, como si éste hubiera recibido en mutuo: "nam proinde ei condici potest si paret eum dare oportere, ac si mutuum accepisset”. No en vano la idéntica protección procesal del mutuum y la solutio indebiti implicó que se encontraran en el mismo título del edicto del pretor (de rebus creditis) y, a raíz de ello, fueran tratados en el mismo libro de los comentarios tardo-clásicos a dicho edicto (vigécimo sexto libro del comentario de Ulpiano, vigécimo octavo del comentario de Paulo). Las semejanzas estructurales entre ambas figuras son evidentes: el accipiensse obliga a transferir al solvens -como el mutuario al mutuante- el quanti ea res est de las cosas indebidamente pagadas ${ }^{44}$, es decir, se obliga a dare rem, así como su propia obligación tuvo por causa una datio del falso deudor; obligación que se hace valer por medio de la condictio.

Los fragmentos conservados en el Digesto que tratan del pago de lo no debido se refieren en la generalidad de los casos a situaciones que bajo circunstancias normales -sin error del solvens en lo concerniente a la existencia del dare oporterehabrían constituido sin más hipótesis de cumplimiento de un contrato de mutuo ${ }^{45}$. Dicho en otros términos: a los ojos de los juristas romanos, los problemas a que daba lugar la solutio indebiti no debieron estar netamente diferenciados desde un punto de vista jurídico -que es el que a fin de cuentas importa- de aquellos procedentes de la mutui datio. Después de todo, las obligaciones de restitución del falso acreedor y el mutuario son esencialmente idénticas (dare oportere estrictamente restitutorio), nacen fundamentalmente del mismo hecho (una datio) ${ }^{46} \mathrm{y}$ se hacen valer con la misma acción (la condictio).

\section{2. 'Re obligatur'. El problema de la contractualidad de la 'solutio indebiti'}

La solutio indebiti causa una obligación real. El que recibe un pago indebido de quien ha incurrido en un error, se obliga p o r la c o s a, al igual que el mutuario: "Is quoque, qui non debitum accepit ab eo, qui per errorem solvit, re obligatur". La expresión quoque (también, igualmente) hace clara alusión a la mutui datio,

${ }^{43}$ Cfr. Betti, Emilio, Sul significato di 'contrahere' in Gaio, cit. (n. 41), p. 66.

${ }^{44}$ Con todo, el solvens puede estar facultado para exigir la restitución del valor económico de los eventuales frutos e incrementos de la cosa. Véase D. 12,6,15pr. (Paul. 10 ad Sab.) y D. 12,6,65,5 (Paul. 17 ad Plaut.).

${ }^{45}$ Vid. las fuentes citadas en n. 25.

${ }^{46}$ La diferencia está en la causa: mientras la datio del mutuante opera credendi causa, la del solvens es solvendi causa. 
figura por medio de la cual se c o n $\mathrm{t} r$ a e una obligación por la cosa (obligatio re contracta) y cuya estructura Gayo acaba de explicar en sus rasgos esenciales en el texto inmediatamente anterior de su manual. Salta a la vista, empero, que Gayo es muy cuidadoso con el lenguaje: si en Gai. 3,90 afirma que se contrae una obligación real por la dación en mutuo ("re contrahitur obligatio [velut] mutui datione”), en Gai. 3,91 se expresa en términos más vagos, limitándose a decir que la obligación -de restitución- del accipiens surje de la adquisición del dominio de las cosas que le han pagado indebidamente (re obligatur). La diferencia es sutil, a primera vista casi imperceptible, pero de enorme significado dogmático: En la solutio indebiti, el accipiens se obliga re, pero no contrae una obligación re (re contrahere). A diferencia de Gai. 3,90, texto que gira en torno a la constitución de una relación obligatoria, en Gai. 3,91 la atención está puesta en la persona del accipiens, quien se convierte en deudor respecto de una obligación de reddere nacida de la adquisición del dominio de las cosas que erróneamente le han sido dadas. No cabe duda de que aquí -al igual que en el caso del mutuo- estamos en presencia de una obligación de restitución, puesto que Gayo dice claramente que procede el ejercicio de la condictio (ei condici potest); pero lo que Gayo no dice es que en virtud de la solutio indebiti se haya con traído una relación obligatoria ${ }^{47}$. El alemán es una lengua que permite apreciar con mayor exactitud esta sutil distinción en la forma de expresarse de Gayo: en Gai. 3,90 se trata de la constitución de un (Rückgewähr-)Schuldverhältnis; en Gai. 3,91, de una (Rückgewähr-) Verpflichtung concreta.

Ciertamente no estamos en presencia de un mero recurso estilístico para evitar una repetición. En lugar de ello, Gayo explica -de una manera que denota una actitud de cautela- el motivo de esta fina distinción terminológica al final del mismo fragmento: quien da una cosa con la intención de cumplir una obligación, quiere más bien extinguir una relación jurídica (el texto habla de negotium) que contraerla ("[...] is, qui solvendi animo dat, magis distrahere vult negotium quam contrahere"). Como es sabido, en Gai. 3,88 se presenta una división dialéctica del genus obligatio en dos species, a saber, las que nacen de un contrato (ex contractu), por una parte, y las que nacen de un delito (ex delicto), por la otra. De ello se sigue una noción de contrato que no se basa en el consentimiento de las partes, sino en la licitud del acto que general la obligación, de modo tal que el contractus se contrapone única y exclusivamente al delictum ${ }^{48}$. En este orden de cosas, la posición de la solutio indebiti dentro del esquema gayano de causae obligationum es más bien inestable. Lo que hace Gayo en este sentido es formular un caveat: el pago

${ }^{47}$ Cfr. Schwarz, Fritz,Die Grundlage der Condictio, cit. (n. 18), p. 8.

48 Gai. 3,88: "Nunc transeamus ad obligationes, quarum summa diuisio in duas species diducitur: omnis enim obligatio uel ex contractu nascitur uel ex delicto". Desde la perspectiva de las actiones in personam (la otra cara de la misma moneda), Gai. 4,2: "In personam actio est, qua agimus, quotiens litigamus cum aliquo, qui nobis uel ex contractu uel ex delicto obligatus est, id est, cum intendimus DARE FACERE PRAESTARE OPORTERE". Una exposición esquemática de la noción gayana de contrato en PARICIO, Javier, Sull'idea di contratto in Gaio, en VACCA (ed.), Causa e contratto nella prospettiva storico-comparatistica (Torino, 1997), pp. 151 ss.; ÉL MISMO, Contrato. La formación de un concepto (Cizur Menor, 2008), pp. 17 ss. 
de lo no debido parece significar la disolución (distrahere) más que la constitución (contrahere) de una relación obligatoria. Gayo manifiesta sus dudas con repecto a calificar la solutio indebiti como contrahere sin más, a pesar de que ciertamente la obligación que de ella nace no es delictual y, con ello, solo cabría incluirla en la categoría del contractus según la summa divisio de Gai. 3,88 ${ }^{49}$.

El caveat gayano al que nos referimos puede dividirse en dos partes: al comienzo de Gai. 3,91 se afirma que el pago de lo no debido ta mbién (quoque) da lugar a una obligación real, lo que aparentemente podría leerse como obligación contraída por medio de una cosa, esto es, una obligación contractual. En efecto, la función de quoque es, precisamente, identificar bajo este respecto -es decir, como causa de una obligación real- a la solutio indebiti con la mutui datio, y el mutuo es según lo dicho en Gai. 3,90 un contrato ("re contrahitur obligatio [...]") 50. Pero entonces la certeza cede el paso a la duda, y un muy cauteloso Gayo señala que, sin embargo, esta especie de obligación ("sed haec species obligationis [...]") no pareciera proceder de un contrato ("non videtur ex contractu consistere").

Llegados a este punto, hay que reconocer que la forma de expresarse de Gayo sobre esta cuestión es algo confusa. Por lo mismo, hay que guardarse de extraer conclusiones apresuradas. El uso de categorías modernas, como son las de negocio jurídico y contrato, entendidos ambos como acuerdos de voluntad, conduciría a una interpretación errónea de la fuente. Es por ello que creemos que no se aprecia una abierta contradicción entre lo expuesto por Gayo y el fragmento de Salvio Juliano, en el cual este último califica la solutio indebiti como negotium (gerere / contrahere). Se trata de D. 12,6,33 (Iul. 39 ad ed.), texto que reza como sigue: "Si in area tua aedificassem et tu aedes possideres, condictio locum non habebit, quia nullum negotium inter nos contraheretur: nam is, qui non debitam pecuniam solverit, hoc ipso aliquid negotii gerit: cum autem aedificium in area sua ab alio positum dominus occupat, nullum negotium contrahit. sed et si is, qui in aliena area aedificasset, ipse possessionem tradidisset, condictionem non habebit, quia nihil accipientis faceret, sed suam rem dominus habere incipiat. et ideo constat, si quis, cum existimaret se heredem esse, insulam hereditariam fulsisset, nullo alio modo quam per retentionem impensas servare posse" 51 .

Juliano afirma que quien edifica en suelo ajeno no puede ejercer la condictio,

${ }^{49}$ En el mismo sentido Laborenz, Martin, Solutio als causa, cit. (n. 28), p. 234.

${ }^{50}$ Cfr. BetTI, Emilio, Sul significato di 'contrahere' in Gaio, cit. (n. 41), p. 66.

51 Sobre la noción de contrahere y el concepto de negotium contractum vid. por ejemplo BETTI, Emilio, Sul significato di 'contrahere' in Gaio, cit. (n. 41), pp. 65 ss.; ÉL MISMO, Sul valore dogmatico della categoria 'contrahere' in giuristi proculiani e sabiniani, en BIDR., 28 (1915), pp. 3 ss.; VocI, Pasquale, La dottrina romana, cit. (n. 29), pp. 46 ss.; Grosso, Giuseppe, Il sistema romano dei contratti (3a edición, Torino, 1963), pp. 29 ss., 38 ss.; Wunner, Sven Erik, Contractus. Sein Wortgebrauch und Willensgehalt im klassischen römischen Recht (Köln/Graz, 1964), pp. 4 ss.; WoŁODKIEWICZ, Witold, Contrahere - contractum - contractus dans le droit romain classique, en KUPISZEWSKI/ÉL MISMO (eds.), Le droit romain et sa reception en Europe (Warszawa, 1978), pp. 297 ss.; Melillo, Generoso, Contrahere, pacisci, transigere. Contributi allo studio del negozio bilaterale romano (Napoli, 1994), pp. 125 ss.; GUZMÁN BRITO, Alejandro, Acto, negocio, contrato y causa en la tradición del derecho europeo e iberoamericano (Cizur Menor, 2005), pp. 33 s.; PARICIO, Contrato, cit. (n. 48), pp. 17 ss. 
a pesar de que en la especie se configura un enriquecimiento injustificado por parte del dominus fundi, quien se hace dueño del edificio en virtud del principio superficies solo cedit. La razón que aduce el jurista para tal decisión es que no se ha celebrado (contraído, dice el texto) un negocio: "condictio locum non habebit, quia nullum negotium inter nos contraheretur". A primera vista, podría parecer que Juliano niega el carácter negocial de la edificación y, como consecuencia de ello, la posibilidad de ejercer la condictio, porque las partes $\mathrm{no}$ h a n co n t r a ta$\mathrm{d} \mathrm{o}$, en el sentido de que no ha habido un acuerdo de voluntades entre las partes involucradas. Lo anterior sería, sin embargo, asumir apriorísticamente nociones jurídicas que no encuentran fundamento textual en la fuente. En efecto, a continuación, Juliano distingue entre el pago de una cantidad de dinero indebida, por una parte, y la ocupación que hace el dominus fundi del edificio construido por un tercero, por la otra, afirmando que en el primer caso se gestiona un negocio ("is, qui non debitam pecuniam solverit, hoc ipso aliquid negotii gerit"), mientras que en el segundo, no se ha contraído negocio alguno ("cum autem aedificium in area sua [...] nullum negotium contrahit"). Pues bien, lo cierto es que ni en la hipótesis de inaedificatio en suelo ajeno ni en la solutio indebiti hay un acuerdo de voluntades entre las personas involucradas, lo que no impidió a Juliano decir que en el pago de lo no debido sí hay un negotium. De ahí que no quede más que concluir que cuando Juliano habla de negotium, no puede estar pensando en clave consensualista, puesto que si así fuera, tanto la edificación como el pago de lo no debido habrían quedado excluidos de esta categoría ${ }^{52}$.

La justificación de la solución julianea se ofrece inmediatamente después, cuando el jurista, continuando su explicación de por qué en los supuestos de inaedificatio no concurre un negotium, señala que si quien edificó hizo poseedor al dominus fundi, no es titular de la condictio porque no ha dado nada a éste ("quia nihil accipientis faceret"), ya que en realidad es el mismo dominus fundi que pasa a ser directamente propietario del edificio, por un modo originario ("sed suam rem dominus habere incipiat"). Aquí se encuentra, pues, la clave para interpretar la fuente: el carácter negocial de la solutio indebiti no viene dado por la existencia de un acuerdo de voluntades, del cual carece en absoluto, sino por el hecho de que ha operado una transferencia de dominio como resultado de una actividad del $d_{a n s^{53}}$. La adquisición del dominio por parte del dominus fundi sobre lo edificado en su terrero no reviste el carácter de negotium gerere/contrahere por ser originaria, no derivada directa e inmediatamente de una acción (una datio) del edificador. La adquisición por parte del accipiens de las cosas pagadas indebidamente, en cambio, sí se circunscribe en el ámbito del negotium gerere /contrahere, ya que pasan a ser suyas en virtud de una actividad del solvens, cual es la datio-indebida, pero válida- de las mismas. Es por ello que el solvens -a diferencia del edificador- se encuentra amparado por la condictio para exigir la restitución de las cosas pagadas por error. En este sentido, el fragmento de Juliano supone una negación de la así

\footnotetext{
52 Saccoccio, Antonio, Si certum petetur, cit. (n. 24), p. 287.

53 Ibíd., p. 289.
} 
llamada condictio sine datione y, por tanto, de la doctrina de los veteres sobre el ex iniusta causa condicere ${ }^{54}$.

En síntesis: la calificación de negotium gerere/contrahere es aplicable a la solutio indebiti porque la adquisición de propiedad por parte del accipiens encuentra su causa inmediata en una acción del solvens (dans), para cuyos efectos carece de importancia que el nacimiento del vínculo jurídico no estuviera en las intenciones de ninguna de las dos partes. No ocurre lo mismo, en cambio, en la inaedificatio, ya que la adquisición del dominio es originaria (dominus rem suam habere incipit) ${ }^{55}$.

En la solutio indebiti, por tanto, estamos en presencia de un negotium por tratarse de la ejecución de una prestación indebida consistente en la transferencia del dominio de una cosa (datio rei), por medio de la cual el solvens pretende extinguir una obligación que, en realidad, no existe ${ }^{56}$. Consecuencialmente, negotium contractum (gestum) no significa lo mismo que contractus, vale decir, en la fuente de Juliano no aparece empleado el verbo contrahere en el sentido más estricto de constitución de una obligatio contracta, sino como el nacimiento de un vínculo jurídico entre dos o más partes en términos generales, lo que vale también para los casos -como este- en que los efectos jurídicos (en la especie, la obligación de restitución) no han sido directamente deseados ${ }^{57}$. En este sentido, la noción de negotium contenida en D. 12,6,33 se podría acercar más a la moderna idea de a c to j u ríd i c o en general (actum quidem generale verbum esse, nos enseña Labeón $)^{58}$ que a la de n e g o c i o j u ríd i co.

De lo anteriormente dicho podemos concluir que el negotium contractum de Juliano y el contrahere / distrahere de Gayo no se refieren exactamente a lo mismo. El negotium contrahere de D. 12,6,33 comprende todo supuesto de transferencia de dominio por medio de una acción del dans / solvens (factum dantis) $)^{59}$. La estructura del pasaje de las Instituciones gayanas permite aseverar que para Gayo -como para Juliano- la solutio indebiti es, efectivamente, un negotium, ya que de lo contrario no habría tenido lugar la transferencia del dominio y no procedería el ejercicio de la condictio. No obstante, Gayo es muy cauteloso y evita calificar esta situación como negotium contrahere, puesto que él está explicando la forma de constituir -hacer nacer, en el lenguaje gayano- relaciones obligatorias a través de contrato en especial (obligationem contrahere), no la gestión de negocios en general como Juliano (negotiumgerere/contrahere), que también puede tener por objeto extinguirtales relaciones. El significado jurídico de la expresión contrahere en Gai. 3,89 ss. es claramente más restringido que el negotium gerere / contrahere de D. 12,6,33, ya que se refiere específicamente al nacimiento de relaciones jurídicas obligatorias por medio de un acto lícito, lo que excluye de plano su extinción ${ }^{60}$. Gayo da por supuesto -no lo explicita- que la solutio indebiti es un negotium,

54 Vid. supra n. 32.

55 SAccoccio, Antonio, Si certum petetur, cit. (n. 24), p. 289.

56 Cfr. Voci, Pasquale, La dottrina romana, cit. (n. 29), p. 12, 105.

${ }_{57}$ Cfr. Melillo, Generoso, Contrahere, pacisci, transigere, cit. (n. 51), p. 130.

58 D. 50,16,19 (Ulp. 11 ad ed.).

59 SACCoccio, Antonio, Si certum petetur, cit. (n. 24), p. 289.

${ }^{60}$ Cfr. Gai. 3,136 = D. 44,7,2,2 (Gai. 3 inst.). 
por lo que el caveat formulado en Gai. 3,91 se dirige más bien a poner en tela de juicio su calidad de contrahere en un sentido mucho más restringido y específico que aquel del que da cuenta el fragmento julianeo.

En todo caso, cabe destacar el hecho que Gayo, quien hasta ahora solo había hablado de obligationes, hace un giro en su lenguaje y, al final de Gai. 3,91, deja de referirse al obligationem contrahere y concluye su discurso sobre la base de la dicotomía negotium contrahere / distrahere. En las res cottidianae, en cambio, volverá a hablar de obligationes: "[...] magis distrahendae obligationis animo quam contrahendae dare videtur" ${ }^{61}$. Es posible que, como sostiene Saccoccio, el motivo de este giro radique en que en Gai. 3,91 se trata de la primera confrontación de Gayo con el pensamiento de Juliano sobre este punto ${ }^{62}$. Tal sutileza en el uso del lenguaje tal vez ya no era necesaria al redactar las res cottidianae, dada la diversa posición sistemática de la solutio indebiti en el esquema de las causae obligationum, como parte de las variae causarum figurae ${ }^{63}$.

Es en este contexto que Gayo pone en entredicho el carácter contractual del pago de lo no debido: no niega que la solutio indebiti constituya un negotium, lo que da más bien como un hecho, toda vez que ha operado una datio de parte del solvens a favor del falso acreedor, sino que el solvens quiera hacer nacer una relación obligatoria (contrahere). En efecto, la argumentación de Gayo parte del supuesto básico de que las cosas dadas en pago se han hecho -válida, pero injustificadamente- propiedad del accipiens por vía negocial. Las aprensiones de Gayo se fundan entonces no en que no haya un acuerdo de voluntades entre solvens y accipiens -cuestión de la cual en la fuente no hay palabra alguna-, sino en que la intención del primero consiste en extinguir una obligación (distrahere) mediante el pago ${ }^{64}$, en vez de hacerla nacer (contrahere en sentido restringido). Como acertadamente afirma D’Ors, "es claro que los reparos de Gayo no están en notar la falta de conventio, como si vislumbrase el cuasicontrato, sino en hacer observar la falta de intención vinculativa, que no es lo mismo exactamente" ${ }^{65}$. Dicho en otros términos: lo que tenía Gayo en mente al poner sutilmente en duda el carácter

${ }^{61}$ D. 44,7,5,3 (Gai. 3 res cott.). Texto completo citado infra n. 70. Para la cuestión sobre el carácter clásico o postclásico del sintagma obligationem contrahere cfr. SEGRÈ, Gino, Sulla classificazione delle cause delle obligationes nelle Istituzioni di Gaio, en Rendiconti della Reale Accademia Nazionale dei Lincei V, Serie VI, Fasc. 3-4, pp. 49 ss. = Scritti vari di diritto romano (Torino, 1952) p. 440 (n. 23), quien se inclina por su procedencia postclásica; en contra ArANGIO-RUIZ, Vincenzo, Ancora sulle res cottidianae. Studio di giurisprudenza postclassica, en Studi in onore di Pietro Bonfante (Milano, 1930), I, pp. 509 ss.

62 Saccoccio, Antonio, Si certum petetur, cit. (n. 24), p. 504.

${ }^{63}$ Vid. infra n. 73.

${ }^{64}$ VoCI, Pasquale, La dottrina romana, cit. (n. 29), pp. 98 s.; cfr. también SARGENTI, Manlio, Svolgimento dell'idea di contratto nel pensiero giuridico romano, en Iura, 39 (1988), pp. 55 ss.; COMA Fort, José María, El derecho de obligaciones en las res cottidianae (Madrid, 1996), p. 26, 147; PARICIO, Javier, Sull'idea di contratto in Gaio, cit. (n. 48), p. 154; Él MISMO, Contrato, cit. (n. 48), p. 31.

${ }^{65}$ D'Ors, Álvaro, Re et verbis, en MoschetTI (ed.), Atti del Congresso Internazionale di Diritto Romano e di Storia del Diritto, Verona 27-28-29 IX 1948 (Milano, 1951), III, p. 280 (n. 62). En contra GuZMán Brito, Alejandro, Acto, negocio, contrato y causa, cit. (n. 51), p. 52, quien ve aquí la necesidad de una conventio entre las partes. Sobre el problema de la voluntad del 
contractual de la solutio indebiti -no lo niega abiertamente: "[...] non uidetur ex contractu consistere [...] magis distrahere uult negotium quam contrahere"- era que el contrato es una causa obligationum, vale decir, un hecho del cual las obligaciones nacen (obligatio ex contractu nascitur), no un modo de extinguirlas, como lo es el pago; es específicamente bajo este punto de vista que la solutio indebiti queda excluida del ámbito contractual.

Consecuencialmente, podemos sostener que en Gai. 3,91 se aprecia una estratificación en lo concerniente a la relación de la solutio indebiti con la mutui datio $^{66}$ : por una parte, la obligación de restitución del accipiens de un indebitum tiene el carácter d e r e a l, del mismo modo que la contraída por el mutuario ("is quoque [...] re obligatur"). Por la otra, la solutio indebiti, a diferencia del mutuum, no es susceptible de ser calificada como contractus, toda vez que supone un negotium distrahere en vez de un negotium contrahere ("sed haec species [...] contrahere" $)^{67}$. Aquí radica el motivo por el cual Gayo no designa la solutio indebiti como obligatio re contracta en especial, sino como re obligari en general: Mutui datio y solutio indebiti, en cuanto dationes rei en sentido técnico-jurídico, dan lugar a obligaciones estrictamente restitutorias susceptibles de hacer valer por medio de la condictio, pero solo la primera hace nacer una obligatio ex contractu (re contrahitur obligatio). Dicho en otros términos: la obligación del accipiens de un indebitum es una obligación r e a l, pero no una obligatio re contracta. En lenguaje moderno, podríamos decir que el pago de lo no debido da lugar a una obligación e x t r a c o n t r a c t u a l, porque "haec species obligationis non videtur ex contractu consistere" ${ }^{\prime 68}$.

Merece ser destacada la circunstancia de que la misma distinción terminológica entre mutui datio y solutio indebiti de Gai. 3,90-91 se observa en las res cottidianae y las Instituciones de Justiniano. Gai. 3,91 es con toda seguridad el modelo

acreedor, dirigida a obligar al deudor, ver recientemente PIETRINI, Stefania, Gai 3.91 e la volontà del creditore volta a 'negotium contrahere', en Index, 44 (2016), pp. 285 ss.

${ }^{66}$ Cfr. VocI, Pasquale, La dottrina romana, cit. (n. 29), p. 99.

${ }^{67}$ No hay argumentos convincentes para estimar este pasaje como un glosema. Sobre el particular vid. COMA ForT, José María, El derecho de obligaciones, cit. (n. 64), pp. 151 ss. y la literatura por él citada.

${ }^{68}$ Se expresa en términos imprecisos HäHnCHEN, Susanne, Die causa condictionis, cit. (n. 36), p. 78: "Die condictio indebiti ist nämlich kein Realkontrakt (3.89-90), wohl aber eine Realobligation". La condictio es la acción por medio de la cual se hace valer la pretensión, no la relación jurídica misma. Cfr. también BETTI, Emilio, Sul significato di 'contrahere' in Gaio, cit. (n. 41), pp. 66 ss.; Riccobono, Salvatore, Dal diritto romano classico al diritto moderno: La dottrina delle 'obligationes quasi ex contractu', en AUPA., 3-4 (1917), p. 287; SANFILIPPO, Cesare, Condictio indebiti, cit. (n. 27), pp. 25 ss.; VocI, Pasquale, La dottrina romana, cit. (n. 29), p. 98, 119 ss.; SChWARZ, Fritz, Die Grundlage der Condictio, cit. (n. 18), p.8, 14; MasCHI, Carlo Alberto, La categoria dei contratti reali, cit. (n. 41), p. 76; SACCOCCIO, Antonio, Si certum petetur, cit. (n. 24), p. 501. 
de I. $3,14,1^{69}$; D. 44,7,5,370, por su parte, el de I. 3,27,671. En el primer par de textos apenas se observan diferencias de estilo: los maestros bizantinos agregaron la frase "daturque agenti contra eum propter repetitionem condicticia actio" seguramente con el objetivo de dejar claro quién es el legitimado activo de la condictio indebiti $^{72}$. En cambio, encontramos más modificaciones entre el fragmento del Digesto extraído de las res cottidianae y el segundo texto de las Instituciones de Justiniano. En efecto, en las res cottidianaese señala que quien, debido a un error de la persona que realiza la prestación, recibe un pago indebido, se obliga como si se hubiese tratado de una dación en mutuo y consecuentemente se puede ejercer contra él la misma acción, esto es, la condictio: "Is quoque, qui non debitum accipit per errorem solventis, obligatur quidem quasi ex mutui datione et eadem actione tenetur". El manual justinianeo, por su parte, enseña sin más y en términos abstractos que el falso acreedor debe (restituir) como si se tratara de un contrato ("quasi ex contractu debere videtur"). A pesar de ciertas diferencias terminológicas que deben haber servido para adaptar el texto gayano al nuevo encuadramiento de la solutio indebiti en la vaga y residual categoría de las variae causarum figurae ${ }^{73}$, el texto de las res cottidianae expresa básicamente las mismas ideas contenidas en Gai. 3,91. Así, en D. 44,7,5,3 leemos que el falso acreedor "obligatur quidem quasi ex mutui datione", en vez del conciso "ac si mutuum accepisset" de las Instituciones; en uno y otro texto, sin embargo, se manifiesta claramente el estrechísimo vínculo entre la solutio indebiti y la mutui datio.

Vistas las cosas en perspectiva histórica, aquí se aprecia la base de la posterior

${ }^{69}$ I. 3,14,1: "Is quoque, qui non debitum accepit ab eo qui per errorem solvit re obligatur: daturque agenti contra eum propter repetitionem condicticia actio; nam proinde ei condici potest SI PARET EUM DARE OPORTERE ac si mutuum accepisset. unde pupillus, si ei sine tutoris auctoritate non debitum per errorem datum est, non tenetur indebiti condictione, non magis quam mutui datione. sed haec species obligationis non videtur ex contractu consistere, cum is qui solvendi animo dat magis distrahere voluit negotium quam contrahere".

${ }^{70}$ D. 44,7,5,3 (Gai. 3 res cott.): "Is quoque, qui non debitum accipit per errorem solventis, obligatur quidem quasi ex mutui datione et eadem actione tenetur, qua debitores creditoribus: sed non potest intellegi is, qui ex ea causa tenetur, ex contractu obligatus esse: qui enim solvit per errorem, magis distrahendae obligationis animo quam contrahendae dare videtur".

${ }^{71}$ I. 3,27,6: "Item is cui quis per errorem non debitum solvit quasi ex contractu debere videtur. adeo enim non intellegitur proprie ex contractu obligatus ut, si certiorem rationem sequamur, magis, ut supra diximus, ex distractu quam ex contractu possit dici obligatus esse: nam qui solvendi animo pecuniam dat, in hoc dare videtur, ut distrahat potius negotium quam contrahat. sed tamen proinde is qui accepit obligatur, ac si mutuum illi daretur, et ideo condictione tenetur".

72 Cfr. Coma Fort, José María, El derecho de obligaciones, cit. (n. 64), p. 145. Segrè, Gino, Sulla classificazione delle cause delle obligationes, cit. (n. 61), p. 439 (n. 21) hace presente que era habitual entre los juristas bizantinos incorporar referencias expresas a la acción a ejercer.

${ }^{73}$ D. 44,7,1 pr. (Gai. 2 res cott.): “Obligationes aut ex contractu nascuntur aut ex maleficio aut proprio quodam iure ex variis causarum figuris”. Cfr. RicCовONO, Salvatore, Dal diritto romano classico al diritto moderno, cit. (n. 68), p. 285 ss.; WOLODKIEWICZ, Witold, Obligationes ex variis causarum figuris (Ricerche sulla classificazione delle fonti delle obbligazioni nel diritto romano classico), en RISG., 14 (1970), pp. 77 ss.; GaLlo, Filippo, Per la ricostruzione e l'utilizzazione della dottrina di Gaio sulle obligationes ex variis causarum figuris, en BIDR., 76 (1973), pp. 171 ss. 
categoría de los cuasicontratos ${ }^{74}$, todavía reconocida en nuestro Código Civil ${ }^{75}$ : en las res cottidianae la solutio indebiti ya no es tratada inmediatamente después de la mutui datio en el marco del re obligari, sino que adquiere, por así decirlo, cierta independencia, al formar parte del indeterminado grupo de las variae causarum figurae (D. 44,7,5pr.-6) ${ }^{76}$, en todo caso, conservando la referencia explícita a la mutui datio. Algo similar ocurre con I. 3,27,6: la obligación del falso acreedor en un supuesto de pago indebido es presentada en términos abstractos como quasi ex contractu, aunque tampoco falta la alusión al "mutuum [...] ac si mutuum illi daretur"). En este orden de cosas, la frase quasi ex contractu de las Instituciones de Justiniano expresa en lo esencial la misma idea contenida en el "quasi ex mutui datione de lasres cottidianae" 77 , toda vez que, de una u otra manera, siempre se trata de la fundamental semejanza estructural de la obligación del accipiens de un indebitum solutum con aquella del accipiens de una mutui datio. Tanto las res cottidianae como las Instituciones de Justiniano tienen, pues, en común, que siguen el modelo de las Instituciones de Gayo al tratar la solutio indebiti desde la perspectiva de la concreta situación del accipiens, cuya obligación de restitución nace de una datio rei realizada por el solvens en la falsa creencia de la existencia de un dare oportere; en ningún caso se habla decontraer un relación obligatoria en virtud de una cosa ("re contrahitur obligatio"), expresión que durante toda la época clásica permaneció reservada única y exclusivamente al mutuum ${ }^{78}$.

Lo dicho significa que, en resumidas cuentas, en toda la así llamada tradición gayano-justinianea se aprecia esencialmente una única representación del pago de lo no debido: el accipiens se encuentra obligado en virtud de un negotium del solvens, más no ex contractu, como si hubiese recibido en mutuo. La procedencia del ejercicio de la "condictio [...] et eadem actione tenetur" según las "res cottidianae [...] et ideo condictione tenetur" en las Instituciones de Justiniano,se debe a la calidad de, si se nos permite la expresión, c u a s i - m u t u o ${ }^{79}$ de la solutio indebiti. Desde esta perspectiva, el pago de lo no debido de muestra como una suerte de reflejo extracontractual del mutuo. El paso definitivo a la plena autonomía de la solutio indebiti como fuente de obligaciones con respecto almutuum aparece recién en I. 3,27,6 (obligatio quasi ex contractu), aunque la semejanza estructural que, en los hechos, existe entre ambas instituciones, no pudo ser totalmente pasada por alto por los maestros bizantinos, que siguen haciendo mención de ella ("[...] is qui accepit obligatur, ac si mutuum illi daretur”). En síntesis: con independencia de la distinta sistemática externa de las materias, el pago de lo no debido constituye

${ }^{74}$ Vid. por todos Coma Fort, José María, El derecho de obligaciones, cit. (n. 64), p. 146.

75 Art. 1437; 2284 ss.

${ }^{76}$ Cfr. Wolodkiewicz, Witold, Obligationes ex variis causarum figuris, cit. (n. 73), pp. 77 ss.; Gallo, Filippo, Per la ricostruzione, cit., pp. 171 ss.; Coma ForT, José María, El derecho de obligaciones, cit. (n. 64), pp. 125 ss., 143 ss.

77 Coma Fort, José María, El derecho de obligaciones, cit. (n. 64), p. 148.

78 Vid. supra n. 6.

79 Sobre el empleo de quasi en las fuentes jurídicas romanas vid. recientemente GUZMÁN BRITO, Alejandro, El significado de "quasi" en el vocabulario de los juristas romanos, en REHJ., 38 (2016), pp. 79 ss., y la literatura por él citada. 
tanto en las Instituciones de Gayo como en las res cottidianae y las Instituciones de Justiniano la causa de una obliga ción real ex tracontractual.

La nueva sistemática de las causae obligationum contenida en las res cottidianae, perfeccionada luego en las Instituciones de Justiniano en lo que concierne a los hechos que no son susceptibles de ser calificados ni como contractus ni como delictum $^{80}$, que reduce la categoría del contrahere a los actos lícitos convencionales que generan obligaciones, trajo consigo que las aprensiones manifestadas por Gayo en sus Instituciones en cuanto al carácter contractual de la solutio indebiti (“ [...] non videtur ex contractu consistere") parezcan confirmadas ${ }^{81}$, puesto que ahora sostiene-aparentemente sin dudar-que no se puede entender que el accipiens de un indebitum se encuentra obligado "ex contractu: sed non potest intellegi is, qui ex ea causa tenetur, ex contractu obligatus esse”. En términos similares, los maestros bizantinos enseñan que en esta misma situación el "accipiens [...] adeo enim non intellegitur proprie ex contractu obligatus [...]" ${ }^{\prime 2}$. Notable sutileza, digna de bizantinos: siguiendo el modelo gayano, evitan decir sin más rodeos que el falso acreedor no se obliga en virtud de un contrato, a pesar de que en su tiempo ello era ya un hecho indiscutible, limitándose a afirmar que no se obliga p r o p i a m e n t e a partir de un contrato, y es que la misma fuente señala in fine que el accipiens se obliga como si se le hubiera dado en mutuo (ac si mutuum illi daretur).

De esta manera, en todos los textos de la tradición gayano-justinianea relativos al pago de lo no debido se manifiesta, en mayor o menor grado, la duda inicial del maestro de época antoniniana: a pesar de que el solvens busca extinguir una relación obligatoria en vez de constituirla y, por ello, la solutio indebiti no puede ser calificada propiamente como contractus, tampoco puede serlo sin más como una categoría totalmente distinta e independiente, puesto que la vinculación estructural con la mutui datio es tan estrecha que ambos institutos jurídicos se muestran, en la práctica, como inseparables. La precaución con la cual Gayo se expresa en sus Instituciones con respecto a este problema de índole netamente sistemático-didáctico, mas no práctico, parece no ser ya tan necesaria en las res cottidianae, dado que la posición sistemática (externa) solutio indebiti es distinta: las inefables variae causarum figurae. No obstante ello, el caveat de Gai. 3,91 se conservó, aunque reverstido bajo una nueva formulación: "qui enim solvit per errorem, magis distrahendae obligationis animo quam contrahendae dare videtur" 83 .

En nuestra opinión, aquí se aprecia una suerte de adecuación de la exposición de Gayo a la creciente -pero jamás definitiva- aceptación en la jurisprudencia

${ }^{80}$ Coma Fort, José María, El derecho de obligaciones, cit. (n. 64), p. 30: "Las variae causarum figurae, por tanto, se han dividido en dos categorías: quasi ex contractu y quasi ex maleficio. En cierto modo, cabe decir que ya venían enunciadas en las res cottidianae y que sólo por motivos de elegancia esquemática y de simetría aparecen expuestas de esa manera en las Institutiones de Justiniano”.

${ }^{81}$ Cfr. Guzmán Brito, Alejandro, Acto, negocio, contrato y causa, cit. (n. 51), p. 52.

82 I. $3,27,6$.

${ }^{83}$ D. 44,7,5,3 (Gai. 3 res cott.). Cfr. I. 3,14,1: "[...] is qui solvendi animo dat magis distrahere voluit negotium quam contrahere; I. 3,27,6: [...] in hoc dare videtur, ut distrahat potius negotium quam contrahat". 
romana de la idea de que a la base de todo contrato habría una conventio ${ }^{84}$, más que la adopción de una nueva idea de contractus. No es concebible que Gayo, en el poco tiempo que debió transcurrir entre la redacción de una obra y otra, haya cambiado de modo tan radical su idea del contrahere, como suele sostenerse en doctrina. Como acertadamente destaca Martini, el nuevo orden de materias de las res cottidianae no significa necesariamente que esta obra contenga una nueva idea de contractus basado en la conventio ${ }^{85}$. De hecho, el tratamiento del re, verbis y consensu contrahere - a diferencia de los delitos- como géneros distintos y, por tanto, como realidades esencialmente autónomas, sin que puedan ser remitidas a un fundamento jurídico (una causa) común ${ }^{86}$, dice mucho más a favor del simple intento de representar la nueva posición de la solutio indebitien el orden externo de materias de las res cottidianae $e^{87}$, que de una mutación dogmática en el pensamiento gayano.

Al menos en lo que concierne a la cuestión del carácter (cuasi)contractual de la solutio indebiti, el Gedankengang de Gayo, el sistema interno de sus Instituciones, permanece prácticamente inalterado en las res cottidianae, y sus ecos pueden oirse incluso en el manual bizantino que encontró en estas obras su modelo principal.

\section{CONCLUSIONES Y PERSPECTIVAS}

Para finalizar, quisieramos resumir los resultados del presente artículo. Nuestro objetivo fue investigar el problema de la contractualidad del pago de lo no debido en las Instituciones de Gayo, cuestión respecto de la cual se aprecia una notable ambigüedad en el lenguaje del maestro antoniniano. Por una parte, de acuerdo a la summa divisio de Gai. 3,88 la obligación del accipiens del indebitum solutum solo puede ser calificada como ex contractu, atentida la circunstancia de que ciertamente no es ilícita (ex delicto), no obstante lo cual Gayo manifiesta sus aprensiones para calificarla como tal, sin que justifique sus dudas en la falta de conventio (hecho que no está en discusión), sino en la falta de intención vinculativa, toda vez que quien paga, aunque lo haga por error a quien no es su verdadero acreedor, más quiere extinguir una obligación que hacerla nacer. Luego, en las res cottidianae, Gayo incluye la solutio indebiti en la vaga y residual categoría de las variae causarum figurae, cuyos supuestos, que en las Instituciones constituían

${ }^{84}$ D. 2,14,1,3 (Ulp. 4 ad ed.): "[...] ut eleganter dicat Pedius nullum esse contractum, nullam obligationem, quae non habeat in se conventionem, sive re sive verbis fiat: nam et stipulatio, quae verbis fit, nisi habeat consensum, nulla est". Sobre esta fuente vid. por ejemplo Garofalo, Luigi, Contratto, obbligazione e convenzione in Sesto Pedio, en Burdese (ed.), Le dottrine del contratto nella giurisprudenza romana (Padova, 2006), pp. 337 ss., y la literatura por él citada.

${ }^{85}$ Martini, Remo, Gaio e le res cottidianae, en AUPA., 55(2012), p. 179 (n. 11). Cfr. ÉL MISMO, Il mito del consenso nella dottrina del contratto, en Iura, 42 (1991), pp. 97 ss.

${ }^{86}$ D. 44,7,4 (Gai. 3 res cott.): "Ex maleficio nascuntur obligationes [...] quae omnia unius generis sunt: nam hae re tantum consistunt, id est ipso maleficio, cum alioquin ex contractu obligationes non tantum re consistant, sed etiam verbis et consensu". La estructura dialéctica se corresponde con Gai. 3,182: "Transeamus nunc ad obligationes, quae ex delicto nascuntur [...] quarum omnium rerum uno genere consistit obligatio, cum ex contractu obligationes in IIII genera diducantur [...]".

${ }^{87}$ Cfr. Riccobono, Salvatore, Dal diritto romano classico al diritto moderno, cit. (n. 68), p. 285. 
contratos, se caracterizan por la falta de acuerdo de voluntades entre las personas involucradas, lo que trae consigo una reducción de la noción de contractus al acto lícito y convencional que genera obligaciones. Aquí se encuentra, pues, el germen de la cuadripartición de las causae obligationum de las Instituciones de Justiniano (y, con ellas, de nuestro Código Civil), donde la solutio indebiti aparece sin más como fuente de obligaciones quasi ex contractu.

En nuestra opinión, Gayo es consistente al aplicar la dicotomía contractusdelictum a las fuentes de las obligaciones: todo hecho generador de obligaciones que no sea contrario a derecho, es susceptible de ser calificado como contrato, incluido el pago de lo no debido. En caso contrario, Gayo no se habría planteado el problema de que, si quería ser coherente consigo mismo, no podía incluir la solutio indebiti entre los contractus sin más, ya que contrahere significa hacer nacer una relación obligatoria, no extinguirla (distrahere), siendo esto último lo que se busca por medio de la solutio. La contractualidad del pago de lo no debido, por tanto, no se encuentra en entredicho en razón de la ausencia de conventio entre solvens y accipiens, que ciertamente no hay, sino en el efecto buscado por el primero, que es disolver un vínculo jurídico, pero no contraerlo. En este orden de cosas, no cabe duda de que la solutio indebiti es un negotium, pero no un contrahere en el sentido propio y más restringido del término según el esquema gayano. Se trata, en definitiva, de dos niveles de argumentación distintos: la solutio indebiti debería ser calificada como contractus, al tratarse de un hecho lícito que genera una obligación (de restituir), pero el acto del solvens no constituye propiamente un supuesto de contrahere en el sentido que le atribuye Gayo, ya que lo que en realidad pretendía el solvens era un distrahere.

El sistema externo de Gayo, su orden de las materias, no es el nuestro; su sistema interno, su Gedankengang, tampoco lo es, y para el historiador del derecho es bueno que así sea: tal vez pueda servir de advertencia contra posibles construcciones anacrónicas y retroproyecciones de dogmas modernos a la experiencia jurídica romana.

BiBLIOGRAFÍA

AlBANESE, Bernardo, Gli atti negoziali nel diritto privato romano (Palermo, 1982).

-- Il processo privato romano delle legis actiones (Palermo, 1987).

Arangio-Ruiz, Vincenzo, Ancora sulle res cottidianae. Studio di giurisprudenza postclassica, en Studi in onore di Pietro Bonfante (Milano, 1930), I, pp. 493-521.

-- Istituzioni di diritto romano (14a edición, Napoli, 1960).

ARCHI, Gian Gualberto, Variazioni in tema di indebiti solutio, en Studi in onore di Vincenzo Arangio Ruiz (Napoli, 1953), III, pp. 335-389.

-- La donazione. Corso di diritto romano (Milano, 1960).

Barrientos Grandon, Javier, El pago de lo no debido en el derecho chileno (Santiago, 2003).

BeHrends, Okko, Der Zwölftafelprozess (Göttingen, 1974).

BЕтті, Emilio, Sul significato di 'contrahere' in Gaio e sulla non-classicità della denominazione 'quasi ex contractu obligatio', en BIDR., 25 (Milano, 1912), pp. 65-88. 
-- Sul valore dogmatico della categoria 'contrahere' in giuristi proculiani e sabiniani, en BIDR., 28 (Milano, 1915), pp. 3-96.

Cannata, Carlo Augusto, Quasi-contratti e quasi-delitti (storia), en ED., 38 (Milano, 1987), pp. 25-34.

-- Cum alterius detrimento et iniuria fieri locupletiorem. L'arricchimento ingiustificato nel diritto romano, en VACCA (ed.), Arricchimento ingiustificato e ripetizione dell'indebito. VI Convegno Internazionale ARISTEC. Padova-Verona-Padova, 25-26-27 settembre 2003 (Torino, 2005), pp. 13-52.

-- Materiali per un corso di fondamenti del diritto europeo (Torino, 2005), I.

COMA FORT, José María, El derecho de obligaciones en las res cottidianae (Madrid, 1996).

CORTESE, Barbara, Indebiti solutio ed arricchimento ingiustificato. Modelli storici, tradizione romanistica e problemi attuali (2a edición, Napoli, 2013).

-- 'Quod sine iusta causa apud aliquem est potest condici' (Napoli, 2013).

Cruz, Sebastião, Da 'solutio'. Terminologia, conceito e características, e análise de vários institutos afins, I: Épocas arcaica e clássica (Coimbra, 1962).

D'Ors, Álvaro, Re et verbis, en Moschetti (ed.), Atti del Congresso Internazionale di Diritto Romano e di Storia del Diritto, Verona 27-28-29 IX 1948 (Milano, 1951), III, pp. 265-303.

-- Réplicas Panormitanas IV. Sobre la supuesta 'condictio' sin 'datio', en Iura, 25 (1974), pp. 1-45.

FARGNol, Iole, 'Alius solvit, alius repetit'. Studi in materia di indebitum condicere (Milano, 2001).

-- Ricerche in tema di furtum. Qui sciens indebitum accipit (Milano, 2006).

FERRINI, Contardo, Storia e teoria del contratto di commodato nel diritto romano, citado de Opere (Milano, 1929), III, pp. 81-203.

FIORI, Roberto, Contrahere e solvere obligationem in Q. Mucio Scevola, en CASCIONE/ Masi Doria (eds.), Fides humanitas ius. Studii in onore di Luigi Labruna (Napoli, 2007), III, 1955-1974.

Frezza, Paolo, Storia del processo civile in Roma fino alla età di Augusto, en ANRW., I 2 (Berlin/New York, 1972), pp. 163-196.

Gallo, Filippo, Per la ricostruzione e l'utilizzazione della dottrina di Gaio sulle obligationes ex variis causarum figuris, en BIDR., 76 (Milano, 1973), pp. 171-224.

Garofalo, Luigi, Contratto, obbligazione e convenzione in Sesto Pedio, en BURdeSE (ed.), Le dottrine del contratto nella giurisprudenza romana (Padova, 2006), pp. 337-378.

GIUFFrè, Vincenzo, Studi sul debito tra esperienza romana e ordinamenti moderni (2a edición, Napoli, 1999).

Grosso, Giuseppe, Obbligazioni. Contenuto e requisiti della prestazione, obbligazioni alternative e generiche ( $2^{\mathrm{a}}$ edición, Torino, 1955).

-- Il sistema romano dei contratti ( $3^{\text {a }}$ edición, Torino, 1963).

GuZmán Brito, Alejandro, Acto, negocio, contrato y causa en la tradición del derecho europeo e iberoamericano (Cizur Menor, 2005).

-- El significado de "quasi" en el vocabulario de los juristas romanos, en REHJ., 38 (Valparaíso, 2016), pp. 79-95.

HäHNCHEN, Susanne, Die causa condictionis. Ein Beitrag zum klassischen römischen Kondiktionenrecht (Berlin, 2003).

-- Sab.-Ulp. D. 12,5,6 und die condictio ex iniusta causa, en ZSS., 121 (Weimar, 2004), pp. 385-395. 
HaRKe, Jan Dirk, Das klassische römische Kondiktionensystem, en Iura, 54 (2003), pp. 49-86.

HeInE, Sonja, Condictio sine datione. Zur Haftung aus ungerechtfertigter Bereicherung im klassischen römischen Recht und zur Entstehung des Bereicherungsrechts im BGB (Berlin, 2006).

JAHR, Günther, Zur iusta causa traditionis, en ZSS., 80 (Weimar, 1963), 141-174.

KASER, Max, Zur 'iusta causa traditionis', en BIDR., 64 (Milano, 1961), pp. 61-97.

-- Römische Privatrecht (2a edición, München, 1971), I.

KaSER, Max; HaCKL, Karl, Das Römische Zivilprozessrecht (2a edición, München, 1996).

KNÜTEL, Rolf, Zum Prinzip der formalen Korrespondenz im römischen Recht, en ZSS., 88 (Weimar, 1971), 67-104.

Kretschmar, Paul, Die Erfüllung. Erster Teil. Historische und dogmatische Grundlagen (Leipzig, 1906).

KuPISCH, Berthold, Ungerechtfertigte Bereicherung. Geschichtliche Entwicklungen (Heidelberg, 1987).

Laborenz, Martin, Solutio als causa. Die Frage des Abstraktionsprinzips im römischen Recht (Köln/Weimar/Wien, 2014).

Lenel, Otto, Das Edictum Perpetuum. Ein Versuch zu seiner Wiederherstellung (3a edición, Leipzig, 1927).

Longo, Giovanni Elio, Pagamento (diritto romano), en NNDI., 12 (Torino, 1965), pp. 316-321.

Magdelain, André, Le consensualisme dans l'édit du préteur (Paris, 1958).

Mantovani, Dario, Le formule del processo privato romano. Per la didattica delle Istituzioni di diritto romano (2a edición, Padova, 1999).

Martini, Remo, Gaio e le res cottidianae, en AUPA., 55 (Palermo, 2012), pp. 97-109.

-- Il mito del consenso nella dottrina del contratto, en Iura, 42 (1991), 171-188.

MaschI, Carlo Alberto, Tutela, fedecommessi, contratti reali (Omissioni nel manoscritto veronese delle Istituzioni di Gaio) en Studi in onore di Edoardo Volterra (Milano, 1971), IV, pp. 667-774.

-- La categoria dei contratti reali. Corso di diritto romano (Milano, 1973).

Melillo, Generoso, Contrahere, pacisci, transigere. Contributi allo studio del negozio bilaterale romano (Napoli, 1994).

NörR, Dieter, Spruchregel und Generalisierung, en ZSS., 89 (Weimar, 1972), pp. 18-93.

Paricio, Javier, Contrato. La formación de un concepto (Cizur Menor, 2008).

-- Sullidea di contratto in Gaio, en VACCA (ed.), Causa e contratto nella prospettiva storico-comparatistica (Torino, 1997), 151-160.

Pastori, Franco, Concetto e struttura della obbligazione nel diritto romano (Milano, 1985).

PelleCCHI, Luigi, L'azione di ripetizione e le qualificazioni del dare in Paul. 17 ad Plaut. D. 12.6.65. Contributo allo studio della condictio, en SDHI., 64 (Romae, 1998), pp. 69-160.

Pietrini, Stefania, Gai 3.91 e la volontà del creditore volta a 'negotium contrahere', en Index, 44 (2016), pp. 285-306.

PIKA, Wolfram, Ex causa furtiva condicere im klassischen römischen Recht (Berlin, 1988).

Pringsheim, Fritz, Bonum et aequum, en ZSS., 52 (Weimar, 1932), pp. 78-155.

Riccobono, Salvatore, Dal diritto romano classico al diritto moderno: La dottrina delle 'obligationes quasi ex contractu', en AUPA., 3-4 (Palermo, 1917), pp. 263-318. 
SACCOCcio, Antonio, Si certum petetur. Dalla condictio dei veteres alle condictiones giustinianee (Milano, 2002).

SANFILIPPO, Cesare, Condictio indebiti, I: Il fondamento dell'obbligazione da indebito (Milano, 1943).

Santoro, Raimondo, Studi sulla condictio, en AUPA., 32 (Palermo, 1971), pp. 181512.

-- Su D. 46.3 .80 (Pomp. 4 ad Quintum Mucium), en AUPA., 55 (Palermo, 2012), 553-618.

Sargenti, Manlio, Pagamento (diritto romano), en ED., 31 (Milano, 1981), pp. 532-540.

-- Svolgimento dellidea di contratto nel pensiero giuridico romano, en Iura, 39 (1988), pp. 24-74.

Schmidun, Bruno, Die römischen Rechtsregeln. Versuch einer Typologie (Köln/Wien, 1970).

SCHWARZ, Fritz, Die Grundlage der Condictio im klassischen römischen Recht (Münster/ Köln, 1952).

Segrè, Gino, Sulla classificazione delle cause delle obligationes nelle Istituzioni di Gaio, en Rendiconti della Reale Accademia Nazionale dei Lincei V, Serie VI, Fasc. 3-4, pp. 49 ss. = Scritti vari di diritto romano (Torino, 1952), pp. 433-442.

SolazzI, Siro, L'estinzione dell'obbligazione nel diritto romano (2a edición, Napoli, 1935), I.

VACCA, Letizia, Osservazioni in tema di 'condictio' e 'arricchimento senza causa' nel

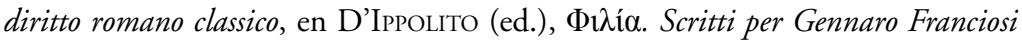
IV (Napoli, 2007), pp. 2709-2732.

VocI, Pasquale, La dottrina romana del contratto (Milano, 1946).

Von Koschembahr-Lyskowski, Ignacy, Die Condictio als Bereicherungsklage im klassischen römischen Recht (Weimar, 1903).

Wegmann Stockebrand, Adolfo, Obligatio re contracta. Ein Beitrag zur sogenannten Kategorie der Realverträge im römischen Recht (Tübingen, 2017).

WolodKIEWICZ, Witold, Contrahere - contractum - contractus dans le droit romain classique, en KUPISZEWSKI/ÉL MISMO (eds.), Le droit romain et sa reception en Europe (Warszawa, 1978), pp. 295-308.

-- Obligationes ex variis causarum figuris (Ricerche sulla classificazione delle fonti delle obbligazioni nel diritto romano classico), en RISG., 14 (1970), pp. 77-227.

Wunner,Sven Erik, Contractus. Sein Wortgebrauch und Willensgehalt im klassischen römischen Recht (Köln/Graz, 1964).

Zimmermann, Reinhard, Ungerechtfertigte Bereicherung und das common law, en VACCA (ed.), Arricchimento ingiustificato e ripetizione dell indebito. VI Convegno Internazionale ARISTEC. Padova-Verona-Padova, 25-26-27 settembre 2003 (Torino, 2005), 255-267. 